\title{
A national population-based study provides insight in the origin of malignancies metastatic to the ovary
}

\author{
Jolien Bruls $^{1} \cdot$ Michiel Simons $^{1} \cdot$ Lucy I. Overbeek ${ }^{2} \cdot$ Johan Bulten $^{1}$ • \\ Leon F. Massuger ${ }^{3} \cdot$ Iris D. Nagtegaal $^{1}$
}

Received: 10 December 2014 / Revised: 26 February 2015 / Accepted: 23 March 2015 / Published online: 19 April 2015

(C) The Author(s) 2015. This article is published with open access at Springerlink.com

\begin{abstract}
A significant proportion of ovarian malignancies consists of metastatic tumors, with a wide variety in site of origin. Differentiating between a primary and metastatic malignancy of the ovaries can be difficult and misdiagnosis might have considerable impact on both treatment and prognosis. To further examine the origin of malignancies metastatic to the ovary, we performed a large-scale, nationwide search for ovarian metastases in the Dutch Pathology Registry (PALGA). All pathology reports concerning malignancies metastatic to the ovary and associated primary tumors in the Netherlands between 2000 and 2010 were collected. Age, year of diagnosis, tumor type, location of the primary tumor, and side of the ovarian tumor were extracted from the database. We identified 2312 patients fulfilling our selection criteria. The most common primary malignancy sites were colon (33.2\%), endometrium (17.1\%), breast (14.3\%), appendix $(7.3 \%)$, and stomach $(4.5 \%)$. The metastases were most frequently bilateral $(46.3 \%)$ followed by unilateral metastases in the right $(26.7 \%)$ and left ovary $(19.8 \%)$, while side was unknown in $7.2 \%$ of cases. Of colorectal carcinomas, only $40.2 \%$ metastasized bilaterally, compared to $63.9 \%$ of breast, $62.9 \%$ of gastric, and $58.9 \%$ of appendix carcinomas. Left-sided colorectal carcinomas most often metastasized to the left ovary $(p<0.0001)$. We found colon carcinomas to be most frequently responsible for metastases to
\end{abstract}

Michiel Simons

Michiel.Simons@radboudumc.nl

1 Department of Pathology 824, Radboud university medical center, PO Box 9101, 6500 HB Nijmegen, The Netherlands

2 PALGA Foundation, Utrecht, The Netherlands

3 Department of Obstetrics and Gynecology, Radboud university medical center, Nijmegen, The Netherlands the ovaries, followed by endometrial and breast carcinomas. Metastases from breast, stomach, and appendix carcinomas were mostly bilateral, whereas metastases from colorectal carcinomas were mostly unilateral. The mechanisms underlying preferred sites for metastasis or side remain unclear.

Keywords Ovarian cancer · Mucinous ovarian carcinoma . Metastasis $\cdot$ Epidemiology

\section{Introduction}

Malignancies metastatic to the ovary are estimated to account for 5-30\% of all ovarian malignancies [1-8]. These most commonly originate from the colorectum, followed by endometrium, stomach, appendix, and breast [1, 2, 6-9]. Differentiating between a primary and metastatic malignancy of the ovaries can be complex as many metastatic carcinomas mimic primary ovarian carcinomas [9]. Mucinous ovarian carcinomas (MOC) are notoriously difficult to distinguish from metastatic adenocarcinomas, and as a consequence, the latter are often misdiagnosed as primary tumors [10-13]. A small study [11] claimed that as many as 40 out of the 52 MOC turned out to be metastases. However, the exact incidence of metastatic disease within the group of MOC is hard to determine. Algorithms as suggested in previous studies $[8,11]$ are not sufficient to identify all carcinomas metastatic to the ovary. Overlapping marker patterns between gynecological and gastrointestinal malignancies limit the usefulness of immunohistochemistry [9].

Since the treatment of choice of primary ovarian malignancies is different from that of metastatic disease to the ovary, misdiagnoses may have important consequences. As survival data are mostly based upon series containing a mixture of metastatic carcinomas and MOC, these are most likely biased. 
Although several studies focused on malignancies metastatic to the ovary, most were based upon small patient populations. Therefore, which malignancies most often metastasize to the ovary and which underlying pathways might be involved remains largely unclear. The purpose of the present large-scale, nationwide study was to gain more insight in primary tumor sites.

\section{Materials and methods}

\section{Study population}

The nationwide network and registry of histo- and cytopathology in the Netherlands (PALGA) codes and saves pathology reports in the Netherlands as of 1971 with nationwide coverage as of 1991 [14]. The search terms "ovary" and "all metastases" were used for the years 2000-2010 to collect all pathology reports concerning malignancies metastatic to the ovary. Conclusions of reports were used for further data analysis. A flow chart of the exclusion process is depicted in Fig. 1.

For each patient, the following items were collected from the pathology report: age at time of diagnosis of ovarian

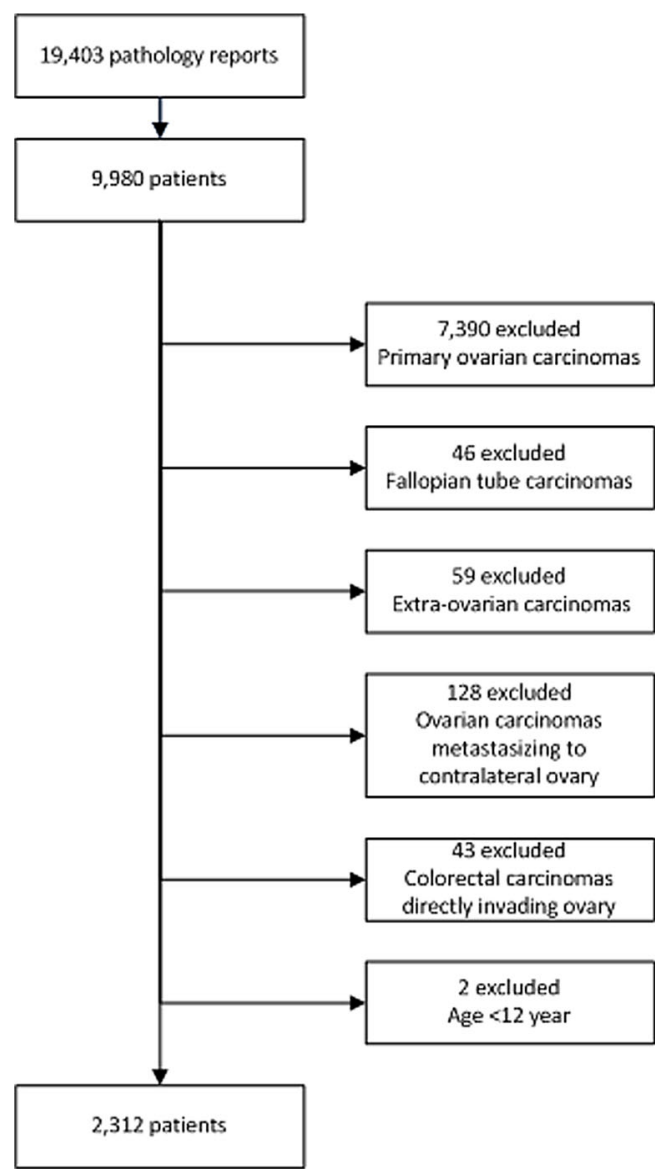

Fig. 1 Flow chart of exclusion process metastasis, year of histological diagnosis, histological type and location of the primary malignancy, and side of the involved ovary. Survival data were not accessible.

Only metastases of which the primary site had been histologically verified were included, and these were classified per organ. Primary squamous or basal cell carcinomas of the skin were excluded. Cases with diagnoses based upon cytology only were excluded from the study. When a carcinoma was clearly not an ovarian primary but histological evidence identifying the primary site was lacking, it was classified as "primary site unknown." Malignancies of which the distinction between primary and metastatic could not be made with certainty were labeled as "indeterminate site." For endometrioid carcinomas, several histological criteria have been proposed to distinguish two synchronous primaries from one tumor being a metastasis from the other, although it is generally accepted that these are not always conclusive and definitive distinction is often not possible [15]. Primary fallopian tube carcinomas were excluded since new insight suggests that these are at least partly precursors of ovarian neoplasms [16]. Carcinomas in the ovary were classified by histological type. Metastatic carcinomas of gastrointestinal tract origin were classified as mucinous carcinoma, unless the pathology report stipulated a different specific histological type. When signet-ring cells were present, the carcinoma was classified as signet-ring cell carcinoma. Carcinomas with more than one histological subtype were classified as mixed. If a colorectal carcinoma was reported to invade the ovary directly, it was excluded since these are considered T4 rather than M1 carcinomas according to the latest TNM classification. Peritoneal lesions composed of abundant extracellular mucin, containing scant simple to focally proliferative mucinous epithelium with little cytologic atypia or mitotic activity, were considered as disseminated peritoneal adenomucinosis (DPAM). Peritoneal lesions composed of more abundant mucinous epithelium with the architectural and cytologic features of carcinoma were considered as peritoneal mucinous carcinomatosis (PMCA). Not all reports mentioned specific criteria or immunohistochemical staining used to reach a final diagnosis. The data used was anonymous. The scientific committee of PALGA approved this study.

\section{Statistical analysis}

All analyses were performed using SPSS (Statistical Package for the social science; SPSS Inc, Chicago, Illinois) version 20.0. The chi-square test was used to compare multiple nominal variables. Distribution of median age was compared using a Mann-Whitney $U$ test, and the sign test was used to compare two nominal variables. A $p$ value $\leq 0.05$ was considered statistically significant. 


\section{Results}

\section{Patient characteristics}

Our search identified 19,403 pathology reports concerning 9980 patients, of which we included 2312 patients (Fig. 1). Median age of all patients with a malignancy metastatic to the ovary was 59 years (range 15-95). Median age of patients with a primary carcinoma of breast $(49.5, p<0.0001)$, lung $(46, p<0.0001)$, stomach $(55, p=0.002)$, and skin $(46.5, p=$ 0.018 ) was significantly lower and that of patients with a primary carcinoma of bladder $(67, p=0.021)$ or endometrium $(64, p<0.0001)$ significantly higher compared to that of patients with a primary carcinoma from other sites. Further details are listed in Table 1.

\section{Primary tumor sites}

Of the 2312 malignancies metastatic to the ovary, the primary tumor was histologically confirmed in 1930 (83.4\%) cases. The most common primary site was colorectum $(n=767$, $33.2 \%)$, followed by endometrium $(n=395,17.1 \%)$, breast $(n=330,14.3 \%)$, appendix $(n=169,7.3 \%)$, and stomach $(n=$ 103, $4.5 \%$ ), as depicted in Fig. 2.

In 348 cases (15.1\%), the primary site was unknown, but in $261(75.0 \%)$ of these, a primary location was suggested in the pathology report. Colorectum $(n=65,18.7 \%)$ was the most commonly suggested primary site, followed by stomach $(n=33,9.5 \%)$, upper gastrointestinal tract (gallbladder, pancreas or stomach) $(n=37,10.7 \%)$, breast $(n=26,7.5 \%)$, appendix $(n=25,7.2 \%)$ or other $(n=14,4.1 \%)$. Gastrointestinal tract without any specification of the location was suggested in 61 cases (17.5\%). In 87 cases $(25.0 \%)$, no primary site was suggested.

In 34 cases $(1.5 \%)$, the primary site was indeterminate. The remaining malignancies metastatic to the ovary $(7.0 \%)$ originated from rare primary sites. Further details on primary sites are listed in Table 1.

\section{Histopathology}

Mucinous carcinoma was the most common histological type ( $n=1082,46.7 \%$ ), followed by signet-ring cell carcinoma ( $n=$ 182, $7.9 \%)$, endometrioid carcinoma $(n=179,7.7 \%)$, and adenocarcinoma not otherwise specified $(n=108,4.6 \%)$. Mucinous carcinomas originated in $66.4 \%(n=717)$ from a colorectal carcinoma $(\mathrm{CRC})$. For signet-ring cell carcinomas, the primary site was most often unknown $(n=60,33.0 \%)$, followed by stomach $(n=52,28.6 \%)$, colon $(n=34,18.8 \%)$, and appendix $(16.5 \%)$. Ductal and lobular carcinomas were responsible for respectively $7.1 \%(n=165)$ and $6.7 \%(n=156)$ of all metastases to the ovary (Table 2).

\section{Tumor side}

Of all ovarian tumors, $46.3 \%$ was bilateral, $19.8 \%$ was left sided, and $26.7 \%$ right sided. In $7.2 \%$ of cases, side was unknown. The primary site of bilateral metastases was the colon in $26.6 \%$, breast in $17.7 \%$, endometrium in $17.1 \%$, appendix in $9.0 \%$, and stomach in $5.7 \%$ of cases while $7.3 \%$ were from a carcinoma in another organ and $16.6 \%$ of unknown primary site. Distribution of primary tumor site was almost the same for metastases to the left and right ovaries as shown in Fig. 2.

Remarkably, only $40.2 \%$ CRC gave rise to bilateral ovarian metastases, compared to $63.9 \%$ of breast, $62.9 \%$ of gastric, and $58.9 \%$ of appendix carcinomas (Fig. 3).

Side of the primary CRC was related to which ovary was affected. Metastases to the left ovary originated more often from carcinomas in the left (descending colon and rectosigmoid) than from those in the right colon (cecum and ascending colon) $(69.4 \%, p<0.0001)$. The difference was not statistically significant for metastases to the right ovary. Carcinomas of the appendix metastasized more often to the right ovary $(71.6 \%, p=0.016)$. For no other organ was a difference in side found.

\section{Discussion}

Differentiating between a primary ovarian malignancy and a malignancy metastatic to the ovary is challenging but important for prognosis and therapy. Our findings, on the as yet largest case series of 2312 primary malignancies metastatic to the ovary, are mostly consistent with earlier smaller studies with a majority of cases originating from gastrointestinal primaries (Table 3). Differences in distribution are partly associated with country of origin and partly due to small patient numbers. Endometrioid carcinomas are a particular problem as it might be difficult to distinguish between an ovarian metastasis of a primary in the endometrium and a synchronous primary endometrioid carcinoma in the ovary, as described earlier. Our dataset includes a relatively low number of uterine sarcomas and carcinosarcomas (less than $1 \%$ of all cases) compared to some other studies. It must be noted that in all studies, the most frequent primary sites were consistently the gastrointestinal tract, breast, and endometrium [1-8].

The relatively high incidence of metastases from CRC is remarkable. In the Netherlands, breast cancer is the most common type of cancer in women (31\%), whereas colorectal cancer accounts for $13 \%$ [17]. Lung cancer is also fairly common $(9 \%)$ but relatively infrequently metastasizes to the ovaries. It is unclear why some primary tumor sites are more likely to metastasize to the ovaries than others.

Spread of appendiceal tumors to the ovaries is a notoriously complex phenomenon [18], which was also reflected in our 


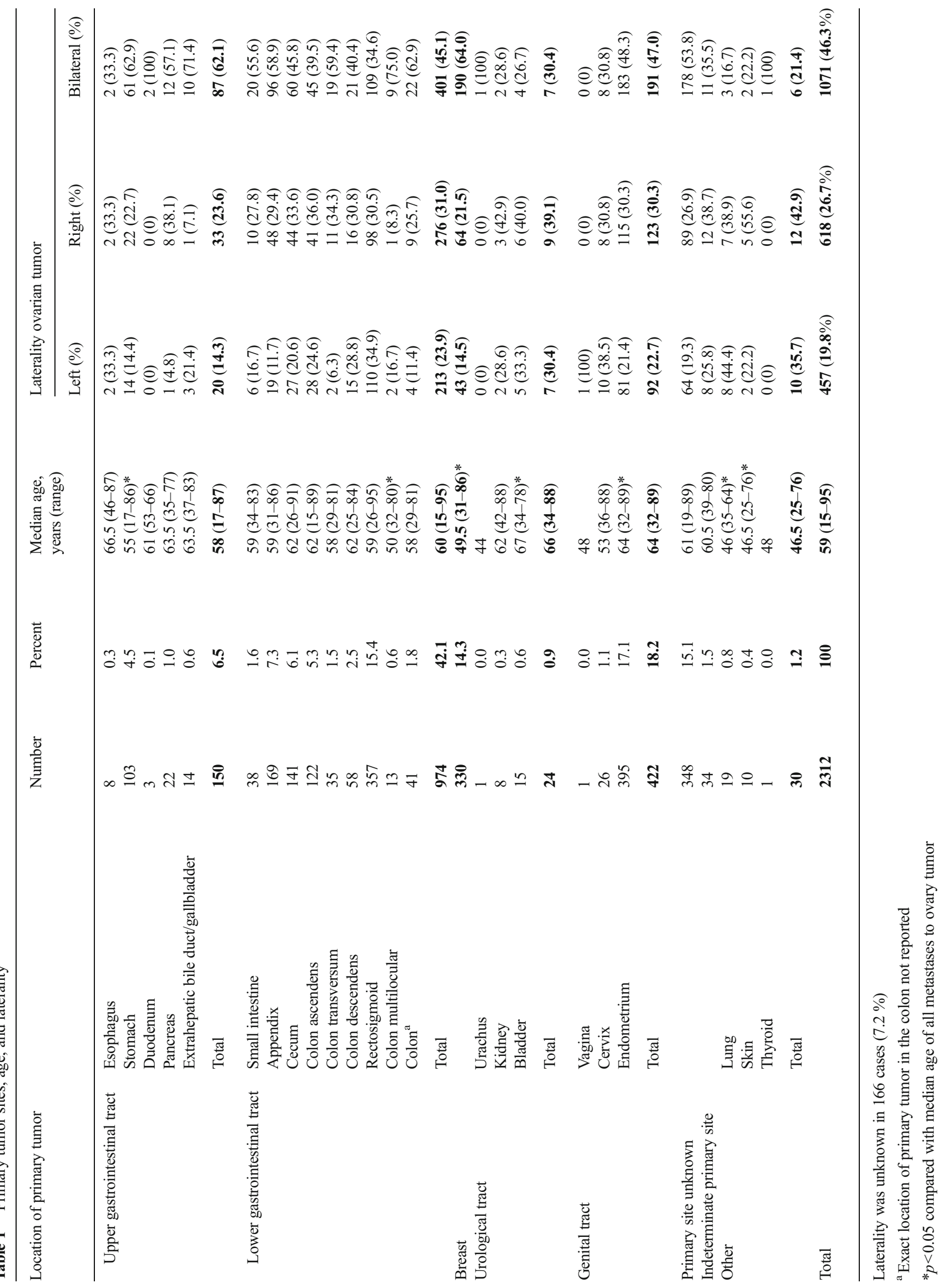



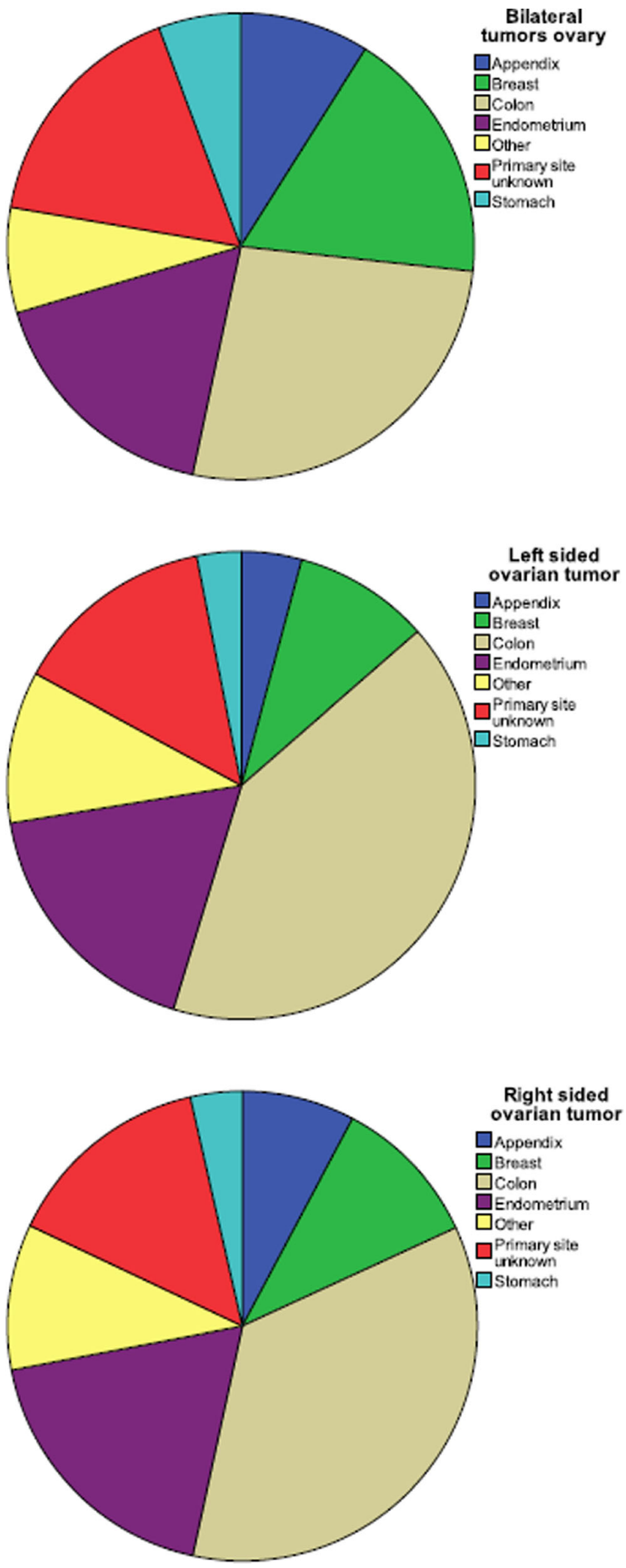

Fig. 2 Side per site of origin

findings. We found 65 low-grade appendiceal tumors (of which 62 associated with DPAM) and 104 appendiceal carcinomas (of which 24 associated with DPAM). Low-grade
Table 2 Cases subdivided according to histology of ovarian tumor

\begin{tabular}{ll}
\hline Histological type & Number $(\%)$ \\
\hline Adenocarcinoma $^{\mathrm{a}}$ & $2124(91.9)$ \\
Mucinous $^{\mathrm{a}}$ & $1167(50.5)$ \\
Serous & $76(3.3)$ \\
Endometrioid & $179(7.7)$ \\
Clear cell & $35(1.5)$ \\
Signet-ring cell & $182(7.9)$ \\
Ductal & $165(7.1)$ \\
Lobular & $156(6.7)$ \\
Other & \\
Sarcoma & \\
Neuro-endocrine carcinoma & $164(7.1)$ \\
Squamous cell carcinoma & $68(2.9)$ \\
Transitional cell carcinoma & $61(2.6)$ \\
Melanoma & $16(0.7)$ \\
Unknown $_{\text {Total }}$ & $12(0.5)$ \\
\end{tabular}

${ }^{\text {a }}$ Includes 79 DPAM associated lesions

${ }^{\mathrm{b}}$ Includes adenocarcinoma NOS, mixed, adenosquamous, undifferentiated, hepatoid, tubular, tubulopapillary, and villoglandular adenocarcinomas

${ }^{\mathrm{c}}$ Includes 25 uterine sarcomas and 43 uterine malignant mesodermal mixed tumors

appendiceal tumor metastases in the ovaries were mostly also low grade, although some presented in the ovary as a carcinoma. Conversely, some appendiceal carcinomas manifested as DPAM, without ovarian involvement by carcinoma. PMCA was not diagnosed in any case which suggests that peritoneal involvement might have been underreported. However, extensive discussion of appendiceal tumors is beyond the scope of this study.

In our series, metastases from an unknown primary site made up the third largest group, with histological features suggestive of a primary site in $75 \%$ of cases. Although this emphasizes the difficulties in distinguishing metastatic from primary malignancies, it is reasonable to believe that the actual number of cases with an unknown primary site is lower. For some patients, the primary site might have been diagnosed but considering factors such as age, physical condition, or prognosis, histological evidence might not have been sought. Incidentally, even though median age for several primary sites such as breast, lung, skin, endometrial, or bladder was significantly different, the wide range prevents age from being useful as a distinguishing feature.

The most frequently seen histological type of carcinoma was mucinous, originating from CRC in most cases. Primary ductal and lobular breast carcinomas were almost equally prevalent (7.1 and $6.7 \%$ of our cases, respectively), even though lobular carcinomas account for only $5-15 \%$ of all breast carcinomas. The loss of expression of the cell-cell 
Fig. 3 Uni- and bilaterality of ovarian metastases of most frequent sites of origin

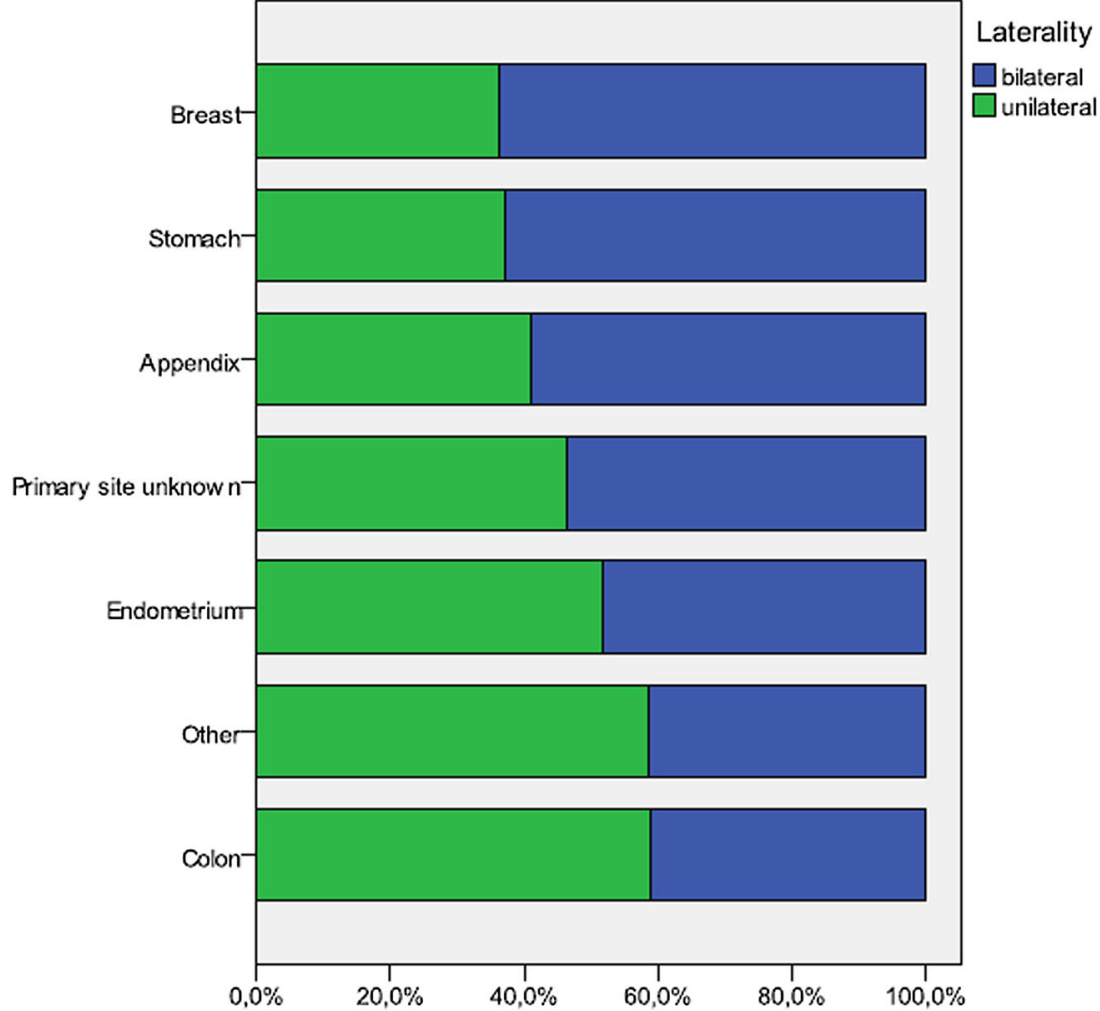

adhesion molecule E-cadherin in lobular carcinomas has been suggested as an explanation for the more frequent spread of lobular carcinomas to the gynecological and gastrointestinal tract [19].

Side of the ovarian tumor (left or right) is a poor predictor of primary site, except for tumors originating from CRC. A leftsided ovarian tumor was more likely to originate from a leftsided CRC. Bilateral involvement of the ovaries occurred in half of the patients and was more common in patients with primary breast, stomach, and appendix carcinomas, whereas CRC more frequently presented with unilateral metastasis to the ovary. Interestingly, Petru et al. [20] found a significantly better 5-year survival rate in patients with unilateral compared to bilateral ovarian involvement. The different patterns of metastasis according to primary site, along with differences in survival, suggest that the metastatic routes followed might not be the same. Chang et al. [21] hypothesized that retrograde lymphatic spread might be responsible for ovarian metastases from gastrointestinal cancer. Our finding that most CRCs tend to metastasize only to the ipsilateral ovary suggests that continuous spread through the peritoneal cavity is involved. How often hematogenous spread is involved is not clear, although the tendency of breast cancer to metastasize to both ovaries supports this route. It is generally accepted that patterns of metastatic spread depend on

Table 3 Studies examining frequencies of primary sites in metastases to the ovary

\begin{tabular}{|c|c|c|c|c|c|c|c|c|}
\hline Author & Number & $\begin{array}{l}\text { Large intestine } \\
(\%)\end{array}$ & $\begin{array}{l}\text { Stomach } \\
(\%)\end{array}$ & $\begin{array}{l}\text { Appendix } \\
(\%)\end{array}$ & $\begin{array}{l}\text { Breast } \\
(\%)\end{array}$ & $\begin{array}{l}\text { Endometrium } \\
(\%)\end{array}$ & $\begin{array}{l}\text { Unknown origin } \\
(\%)\end{array}$ & $\begin{array}{l}\text { Other } \\
(\%)\end{array}$ \\
\hline Demopoulos 1987 & 96 & $12(13)$ & $6(6)$ & $1(1)$ & $32(33)$ & $14(15)$ & 0 & $31(32)$ \\
\hline Petru $1992^{\mathrm{a}}$ & 82 & $23(28)$ & $22(27)$ & 0 & $28(34)$ & 0 & 0 & $9(11)$ \\
\hline Yada-Hashimoto 2003 & 64 & $7(11)$ & $15(23)$ & $1(2)$ & $9(14)$ & $15(23)$ & $1(2)$ & $16(25)$ \\
\hline Moore $2004^{\mathrm{a}}$ & 59 & $19(32)$ & $4(7)$ & $12(20)$ & $5(9)$ & 0 & $10(17)$ & $9(15)$ \\
\hline Yemelyanova $2008^{\mathrm{b}}$ & 142 & $46(32)$ & $5(4)$ & $26(18)$ & 0 & 0 & 0 & $65(46)$ \\
\hline De Waal 2009 & 116 & $23(20)$ & $7(6)$ & $2(2)$ & $32(27)$ & $23(20)$ & $9(8)$ & $20(17)$ \\
\hline Kondi-Pafiti 2011 & 97 & $15(15)$ & $24(25)$ & $3(3)$ & $15(15)$ & $22(23)$ & 0 & $18(19)$ \\
\hline Bruls 2013 & 2312 & $767(33)$ & $103(5)$ & $169(7)$ & $330(14)$ & 395 (17) & $382(17)$ & $166(7)$ \\
\hline
\end{tabular}

${ }^{a}$ Only non-genital primary tumor sites were included

${ }^{\mathrm{b}}$ Only mucinous tumors were included 
specific characteristics of tumor cells with metastatic potential as well as the micro-environment of recipient tissue [22-24]. Between organs, properties of the extracellular matrix and vascular endothelial cells are different in terms of homing ligands and production of regulatory factors $[25,26]$. While it is still not fully understood why some tumors preferentially metastasize to particular sites or bilateral rather than unilateral, direct transperitoneal spread is an important mechanism in our case series consisting mostly of primary malignancies in the abdomen or pelvis.

We only included histologically confirmed cases but did not revise histology. As for many cases, the criteria used to conclude that an ovarian malignancy was a metastasis from a primary elsewhere, were not available, these were not taken into consideration. While immunohistochemistry is often inconclusive, PAX-8 might prove useful as a marker relatively specific for mucinous ovarian carcinomas [27, 28]. A limitation of our study is its inclusion of patients from a geographically defined area only and in a specific time frame. However, comprehensive coverage of the whole Dutch population in the PALGA database does provide solid evidence of the site of primary malignancies metastatic to the ovary.

In summary, in our large patient series, colon is the most frequent primary site of a malignancy metastatic to the ovary, followed by endometrium and breast. Metastases from breast, stomach, and appendix carcinomas were mostly bilateral. Colorectal carcinoma metastases were mostly unilateral, with a trend for the side of CRC to correspond to the side of the ovarian metastasis. Mechanisms determining patterns of metastasis are still largely unclear, but our observations suggest that these might be different per primary tumor type.

Conflict of interest The authors declare that they have no conflict of interest.

Open Access This article is distributed under the terms of the Creative Commons Attribution 4.0 International License (http:// creativecommons.org/licenses/by/4.0/), which permits unrestricted use, distribution, and reproduction in any medium, provided you give appropriate credit to the original author(s) and the source, provide a link to the Creative Commons license, and indicate if changes were made.

\section{References}

1. de Waal YR, Thomas CM, Oei AL, Sweep FC, Massuger LF (2009) Secondary ovarian malignancies: frequency, origin, and characteristics. Int J Gynecol Cancer 19:1160-1165. doi:10.1111/ IGC.0b013e3181b33cce

2. Kondi-Pafiti A, Kairi-Vasilatou E, Iavazzo C, Dastamani C, Bakalianou K, Liapis A, Hassiakos D, Fotiou S (2011) Metastatic neoplasms of the ovaries: a clinicopathological study of 97 cases. Arch Gynecol Obstet 284:1283-1288. doi:10.1007/s00404-0111847-4
3. Demopoulos RI, Touger L, Dubin N (1987) Secondary ovarian carcinoma: a clinical and pathological evaluation. Int $\mathrm{J}$ Gynecol Pathol 6:166-175

4. Yada-Hashimoto N, Yamamoto T, Kamiura S, Seino H, Ohira H, Sawai K, Kimura T, Saji F (2003) Metastatic ovarian tumors: a review of 64 cases. Gynecol Oncol 89:314-317

5. Khunamornpong S, Suprasert P, Chiangmai WN, Siriaunkgul S (2006) Metastatic tumors to the ovaries: a study of 170 cases in northern Thailand. Int J Gynecol Cancer 16(Suppl 1):132-138. doi: 10.1111/j.1525-1438.2006.00302.x

6. Antila R, Jalkanen J, Heikinheimo O (2006) Comparison of secondary and primary ovarian malignancies reveals differences in their pre- and perioperative characteristics. Gynecol Oncol 101: 97-101. doi:10.1016/j.ygyno.2005.09.046

7. Moore RG, Chung M, Granai CO, Gajewski W, Steinhoff MM (2004) Incidence of metastasis to the ovaries from nongenital tract primary tumors. Gynecol Oncol 93:87-91. doi:10.1016/j.ygyno. 2003.12.039

8. Yemelyanova AV, Vang R, Judson $\mathrm{K}$, Wu LS, Ronnett BM (2008) Distinction of primary and metastatic mucinous tumors involving the ovary: analysis of size and laterality data by primary site with reevaluation of an algorithm for tumor classification. Am J Surg Pathol 32:128-138. doi:10.1097/PAS. 0b013e3180690d2d

9. McCluggage WG, Wilkinson N (2005) Metastatic neoplasms involving the ovary: a review with an emphasis on morphological and immunohistochemical features. Histopathology 47:231-247. doi: 10.1111/j.1365-2559.2005.02194.x

10. Lee KR, Young RH (2003) The distinction between primary and metastatic mucinous carcinomas of the ovary: gross and histologic findings in 50 cases. Am J Surg Pathol 27:281-292

11. Seidman JD, Kurman RJ, Ronnett BM (2003) Primary and metastatic mucinous adenocarcinomas in the ovaries: incidence in routine practice with a new approach to improve intraoperative diagnosis. Am J Surg Pathol 27:985-993

12. Zaino RJ, Brady MF, Lele SM, Michael H, Greer B, Bookman MA (2011) Advanced stage mucinous adenocarcinoma of the ovary is both rare and highly lethal: a Gynecologic Oncology Group study. Cancer 117:554-562. doi:10.1002/cncr.25460

13. Hart WR (2005) Mucinous tumors of the ovary: a review. Int $\mathbf{J}$ Gynecol Pathol 24:4-25

14. Casparie M, Tiebosch AT, Burger G, Blauwgeers H, van de Pol A, van Krieken JH, Meijer GA (2007) Pathology databanking and biobanking in The Netherlands, a central role for PALGA, the nationwide histopathology and cytopathology data network and archive. Cell Oncol 29:19-24

15. Ulbright TM, Roth LM (1985) Metastatic and independent cancers of the endometrium and ovary: a clinicopathologic study of 34 cases. Hum Pathol 16:28-34

16. Kurman RJ, Shih Ie M (2011) Molecular pathogenesis and extraovarian origin of epithelial ovarian cancer-shifting the paradigm. Hum Pathol 42:918-931. doi:10.1016/j.humpath.2011.03. 003

17. Cancer Statistics, Dutch Cancer Registry. www.cijfersoverkanker.nl

18. Misdraji J (2010) Appendiceal mucinous neoplasms: controversial issues. Arch Pathol Lab Med 134:864-870. doi:10.1043/15432165-134.6.864

19. Sastre-Garau X, Jouve M, Asselain B, Vincent-Salomon A, Beuzeboc P, Dorval T, Durand JC, Fourquet A, Pouillart P (1996) Infiltrating lobular carcinoma of the breast. Clinicopathologic analysis of 975 cases with reference to data on conservative therapy and metastatic patterns. Cancer 77:113-120. doi:10.1002/(sici)10970142(19960101)77:1<113::aid-cncr19>3.0.c0;2-8

20. Petru E, Pickel H, Heydarfadai M, Lahousen M, Haas J, Schaider $\mathrm{H}$, Tamussino K (1992) Nongenital cancers metastatic to the ovary. Gynecol Oncol 44:83-86 
21. Chang TC, Changchien CC, Tseng CW, Lai CH, Tseng CJ, Lin SE, Wang CS, Huang KJ, Chou HH, Ma YY, Hsueh S, Eng HL, Fan HA (1997) Retrograde lymphatic spread: a likely route for metastatic ovarian cancers of gastrointestinal origin. Gynecol Oncol 66: 372-377. doi:10.1006/gyno.1997.4793

22. Mathot L, Stenninger J (2012) Behavior of seeds and soil in the mechanism of metastasis: a deeper understanding. Cancer Sci 103: 626-631. doi:10.1111/j.1349-7006.2011.02195.x

23. Paget S (1989) The distribution of secondary growths in cancer of the breast. 1889. Cancer Metastasis Rev 8:98-101

24. Hanahan D, Weinberg RA (2011) Hallmarks of cancer: the next generation. Cell 144:646-674. doi:10.1016/j.cell.2011. 02.013
25. Langley RR, Fidler IJ (2007) Tumor cell-organ microenvironment interactions in the pathogenesis of cancer metastasis. Endocr Rev 28:297-321. doi:10.1210/er.2006-0027

26. Sleeman JP, Christofori G, Fodde R, Collard JG, Berx G, Decraene C, Ruegg C (2012) Concepts of metastasis in flux: the stromal progression model. Semin Cancer Biol 22:174-186. doi:10.1016/ j.semcancer.2012.02.007

27. Ozcan A, Shen SS, Hamilton C, Anjana K, Coffey D, Krishnan B, Truong LD (2011) PAX 8 expression in non-neoplastic tissues, primary tumors, and metastatic tumors: a comprehensive immunohistochemical study. Mod Pathol 24:751-764. doi:10.1038/ modpathol.2011.3

28. Ordonez NG (2012) Value of PAX 8 immunostaining in tumor diagnosis: a review and update. Adv Anat Pathol 19:140-151. doi:10.1097/PAP.0b013e318253465d 